\title{
A photonics Masters program at a regional metropolitan university
}

Jack Glassman, Hernando Garcia, Abdullatif Hamad, David Kaplan

Jack G. Glassman, Hernando Garcia, Abdullatif Y. Hamad, David H. Kaplan, "A photonics Masters program at a regional metropolitan university," Proc. SPIE 9665, Tenth International Topical Meeting on Education and Training in Optics and Photonics, 96651T (3 June 2007); doi: 10.1117/12.2207803

SDIE Event: Tenth International Topical Meeting on Education and Training in Optics and Photonics, 2007, Ottawa, Ontario, Canada 


\title{
A Photonics Masters Program at a Regional Metropolitan University
}

\author{
Jack G. Glassman, Hernando Garcia, Abdullatif Y. Hamad, and David H. Kaplan \\ Dept. of Physics, Southern Illinois University Edwardsville \\ Edwardsville, Illinois 62026
}

\begin{abstract}
Many Physics students opt for a master's degree in Physics without plans for pursuing a doctorate in the future. These students typically wish to find jobs in industry after receiving the M.S. degree. The traditional Physics master's degree program, with courses mirroring those of the first year of a program leading to a Ph.D., is not addressed to the needs of many of these students. On the other hand, offering broad and extensive training for a variety of careers in industry may place burdens on the resources of smaller graduate programs. In this presentation, we describe a new Optics-Photonics program and course sequences developed for a small graduate Physics department at a regional metropolitan university (Southern Illinois University Edwardsville) which has successfully placed students in rewarding careers in industry that heavily utilize their Physics training.
\end{abstract}

